\title{
Effect of microstructure on tensile properties of Ti-17 alloys forged using a 1500-ton forging simulator
}

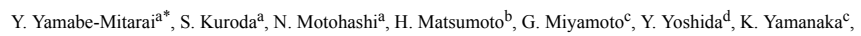

\author{
M. Niinomi ${ }^{\text {c, e, f, g, Y. Itsumi }}{ }^{\text {h }}$
}

a National Institute for Materials Science, Tsukuba, Japan

b Kagawa University, Takamatsu, Japan

c Institute for Materials Research, Tohoku University, Sendai, Japan

d Faculty of engineering and graduate school of engineering, Gifu University, Gifu, Japan

e Department of Science and Technology, Meijo University, Nagoya, Japan.

f Department ofMaterials and Manufacturing Science, Graduate School of Engineering, Osaka University,Osaka, Japan.

g Institute of Materials and Systems for Sustainability, Nagoya University, Nagoya, Japan.

h Kobe Steel, LTD., Takasago, Japan.

*Mitarai.yoko@nims.go.jp

\section{$\underline{\text { Abstract }}$}

Microstructure dependence on mechanical properties were investigated for Ti- 17 forged at temperatures between 700 and $850{ }^{\circ} \mathrm{C}$ with deformation ratio from 33 to $80 \%$, and solutiontreated at $800^{\circ} \mathrm{C}$ for 4 hours and aged at $620^{\circ} \mathrm{C}$ for 8 hours. The microstructure was observed after solution and aging treatments. The volume fraction and the size of the primary alpha phase was controlled by solution treatment temperature, not forging temperature and deformation ratio. Forging temperature affected the morphology of grain boundary (GB) alpha phase. Deformation ratio affected the grain size and the aspect ratio of the horizontal and vertical grain size of the prior beta phase. The tensile strength was investigated at room temperature, 450 , and $600{ }^{\circ} \mathrm{C}$. Forging temperature and deformation ratio did not affect the tensile strength because there is no large difference of the volume fraction of the alphaphase. On the other hand, the elongation and the reduction of area increased with increase of the aspect ratio of the prior beta grains; that means, increase of the deformation ratio. Raising of forging temperature also increased elongation and reduction of area due to the film-like GB alphaphase.

\section{Introduction}

The mechanical properties of Ti alloys for aero engines are highly influenced by their microstructure, which is controlled by thermo-mechanical processing, generally forging and heat treatment. In the aviation industry, processing technology which can produce materials with desirable mechanical properties are strongly required. A plenty of researches have been performed to understand hot deformation behavior and the mechanism, and the microstructure evolution of Ti alloys, such as Ti-64, Ti6242, TIMETAL 834, Ti-17 and some of beta Ti alloys [for example 1-6]. Dynamic recovery and dynamic recrystallization are focused for thermo-mechanical processing in the beta phase field. While, spheroidization or globularization of the alpha phase is focused for thermos-mechanical processing in the alpha + beta phase field. Various kinetics models to predict recrystallization have been proposed [1-6].

A 50,000 ton hydraulic pressure forging press was installed to produce large components of Ti alloys and Ni base superalloys in Japan Aeroforge, Ltd. in 2013 in Japan. Then, the national project, Cross-ministerial Strategic Innovation Promotion Program, SIP was launched in 2014. It was 5 years project and finished at March in 2019. To obtain comprehensive data set from the plastic deformation, the microstructure and the mechanical properties of Ti alloys, a 1500 ton hydraulic pressure forging press was installed. Since a disk-like materials with a diameter of approximately $270 \mathrm{~mm}$ and a height of $50 \mathrm{~mm}$, for example, can be produced using the 1500 ton forging press, samples for microstructure observation and mechanical property test can be obtained from the same position, and the correlation between the forging condition, the microstructure, and the mechanical properties was investigated.

(C) The Authors, published by EDP Sciences. This is an open access article distributed under the terms of the Creative Commons Attribution License 4.0 (http://creativecommons.org/licenses/by/4.0/). 
The Ti-17 (Ti-5Al-2Sn-2Zr-4Cr-4 Mo, mass \%) alloy was selected as the target material. The Ti-17 is a near beta Ti alloy that consists of alpha precipitates and beta matrix. It is used up to $450{ }^{\circ} \mathrm{C}$ as compressor disks in jet engines due to its high strength, good creep resistance, and good fatigue properties. The hot deformation behavior and the microstructural evolution in the beta phase field was investigated using small forging press and the constitutive model and the processing map were established [7]. The microstructure prediction model for dynamic recrystallization of the beta phase, globularization of the alpha phase, the aspect ratio and the average ferret-diameter of the alpha phase was also proposed for as forged Ti-17 alloy [8]. The microstructure evolution during solution and aging treatments was investigated and the prediction model for the volume fraction and the size of the alpha phase was established [9]. To apply these prediction model to forged materials by 1500 ton forging press, the coefficients of the friction and the thermal transfer were determined by the comparison of the experiments with the hot forging emulating system and Finite Element analysis (FEM) [10].

The coefficients of the friction and the thermal transfer are used to simulate strain and temperature distribution and their change during forging as interfacial conditions. The microstructures of as-forged samples and the solution treated and aged samples using the 1500 ton forging press were observed and the prediction models were improved to describe them precisely. The effect of the microstructure factors such as the volume fraction of the primary and secondary alpha phase and the grain size and the aspect ratio of the beta phase on tensile properties and fatigue was also investigated for samples forged using 1500 ton forging press, solution treated and aged materials [11, 12]. These models were connected each other as a subroutine and inserted to FEM software to simulate microstructure and tensile strength.

In this study, the effect of forging conditions, such as the forging temperature and the deformation ratio, on the microstructure was investigated for Ti-17. The mechanical properties was correlated with the microstructure factors such as volume fraction of the alpha phase, the morphology of grain boundary (GB) alpha phase and aspect ratio of the prior beta phase.

\section{Experimental procedure}

Cylindrical Ti-17 sample with a diameter of $134 \mathrm{~mm}$ and a height of $192 \mathrm{~mm}$ were heat-treated in the beta phase field and forged at temperature range between 700 and $850{ }^{\circ} \mathrm{C}$ and the deformation ratio between 33 and $80 \%$ with a strain rate of $0.033 / \mathrm{s}$ using the 1500 ton forging press and then air cooled. The forging conditions are summarized in Table 1 . The final size of the forged sample was approximately $270 \mathrm{~mm}$ in dimeter and $50 \mathrm{~mm}$ in height. The forged disk-like materials were solution-treated at $800{ }^{\circ} \mathrm{C}$ for 4 hours, followed by water quenching, and aged at $620{ }^{\circ} \mathrm{C}$ for 8 hours, followed by air cooling. The tensile test specimens with $4 \mathrm{~mm}$ diameter and $16 \mathrm{~mm}$ gage length were cut parallel to direction of circumference from the $\mathrm{D} / 4$ position (D is diameter) in the heat-treated materials. The tensile test was performed according to ASTM E8 condition at room temperature (RT) and ASTM E21 condition at 450 and $600{ }^{\circ} \mathrm{C}$. The microstructure was observed as a sample near the tensile test specimen using scanning electron microscopy (SEM, JEOL 7000F or 7200F) with electron backscatter diffraction (EBSD) at $20 \mathrm{kV}$. The grain size of prior beta phase was identified using EBSD. The sum of the volume fraction of the primary and GB alpha phase was identified using EBSD. Then, the volume fraction of GB alpha phase was identified using SEM image analysis by OLYMPUS Stream software. The volume fraction of the primary alpha phase was determined by subtracting the volume fraction of GB alpha phase from the sum of volume fraction of the primary and GB alpha phase obtained by EBSD. The total volume fraction of the alpha phase was measured using X-ray diffractometry (Bruker, Advance D8 or RIGAKU SmartLab). Then, the volume fraction of secondary alpha was calculated by subtracting the volume fraction of primary alpha and GB alpha from the total volume fraction of the alpha phase because it is difficult to identify the volume fraction of secondary alpha by EBSD due to their small size.

Table 1 The forging conditions

\begin{tabular}{|c|c|c|c|c|c|}
\hline $\begin{array}{l}\text { Forging temp } \\
\left({ }^{\circ} \mathrm{C}\right)\end{array}$ & 33 & 50 & 67 & 75 & 80 \\
\hline 700 & & & & $\circ$ & \\
\hline 750 & & & & $\circ$ & \\
\hline 800 & $\circ$ & 0 & O & $\circ$ & 0 \\
\hline 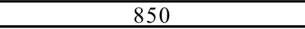 & & & & 0 & \\
\hline
\end{tabular}

\section{Results and Discussion}

Microstructure

The microstructure evolution was clarified by observation of the microstructure of as-forged, solution-treated and aged samples [11]. It was found that the beta phase exhibited and the alpha phase formed at only grain boundary during forging. The fine acicular alpha (primary alpha) precipitated inside the beta grains during cooling after forging. The fine acicular alpha and GB alpha phase grew during the solution treatment. Especially, the GB alpha phase became granular shape or film-like shape along grain boundaries depending on the forging and heat treatment condition. Further aging treatment caused the fine secondary alpha phase between primary alpha phase in the beta matrix. 
The microstructures of solution-treated and aged samples after forging at $800{ }^{\circ} \mathrm{C}$ with various deformation ratio are represented in Fig. 1. The acicular primary alpha phase which formed during solution treatment and the fine secondary alpha phase which formed during aging treatment were observed in the beta matrix in the all samples with various deformation ratio. The size of the primary alpha phase was approximately 2-30 micro $\mathrm{m}$ in length and 0.5 micro micro $\mathrm{m}$ in thickness, in the all observed samples. The GB alpha phase is shown in Fig. 2. The film-like shape alpha phase was formed along grain boundaries in the all observed samples. The volume fraction of the primary, secondary, and GB alpha phase analyzed by EBSD, X-ray diffractometry, and image analysis are shown in Fig. 3. The volume fraction of primary alpha phase was approximately $50 \%$ up to $75 \%$ deformation ratio. At deformation ratio of $80 \%$, the volume fraction of primary alpha phase decreased because the volume fraction of GB alpha phase increased. Since the sum of the volume fraction of the primary and GB alpha phase is almost the same for the observed samples, the volume fraction of secondary alpha phase was approximately $10 \%$.

It is considered that the deformation ratio affects strain introduced during forging in the forged samples. The strain is considered to affect nucleation of the primary alpha phase. However, since the solution-treatment temperature was $800{ }^{\circ} \mathrm{C}$ for all the samples, it is considered that the primary alpha phase grew and became the equilibrium size during solution treatment. The observation indicates that the volume fraction of primary alpha phase is governed by the solution-treatment temperature. The average length and the thickness of the primary alpha phase was approximately 10 micro $\mathrm{m}$ and 0.5 micro $\mathrm{m}$, respectively for the all observed samples. There is no effect for the size of the primary alpha phase by deformation ratio. Only the GB alpha phase seems to increase when deformation ratio was $80 \%$. Maybe because the strain increased around GB caused growth of GB alpha phase.
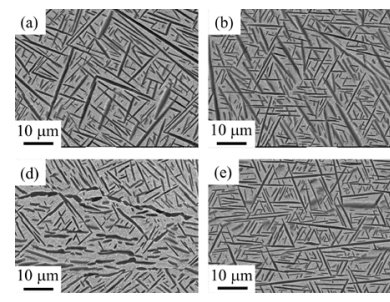

Fig. 1 Backscattered electron images of Ti-17 forged samples at $800{ }^{\circ} \mathrm{C}$ with (a) 33 , (b) 50 , (c) 67 , (d) 75 , and (e) $80 \%$ of deformation ratio followed by air cooling and subjected to solution treatment at $800{ }^{\circ} \mathrm{C}$ for 4 hours followed by water quenching and aging treatment at $620^{\circ} \mathrm{C}$
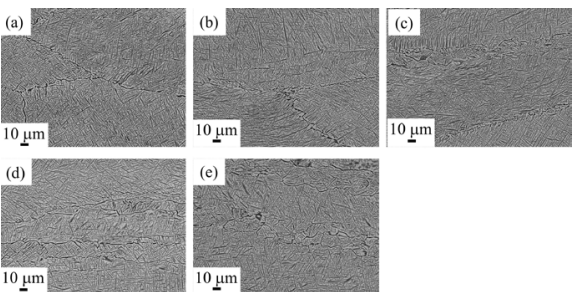

Fig. 2 Low magnification backscattered electron images of Ti- 17 forged samples at $800{ }^{\circ} \mathrm{C}$ with (a) 33 , (b) 50 , (c) 67 , (d) 75 , and (e) $80 \%$ of deformation ratio followed by air cooling and subjected to solution treatment at $800{ }^{\circ} \mathrm{C}$ for 4 hours followed by water quenching and aging treatment at $620{ }^{\circ} \mathrm{C}$ for 8 hours followed by air cooling.

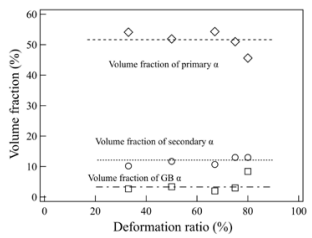

Fig. 3 Volume fraction of the alpha phase for the deformation ratio.

The microstructures of the samples forged at various forging temperature are shown in Fig. 4 [11]. It was found that the forging temperature affected only the morphology of GB alpha phase; that is, the granular shape alpha phase was observed along grain boundaries for the samples forged at 700 and $750{ }^{\circ} \mathrm{C}$. On the other hand, film-like thin alpha phase was formed for the samples forged at 800 and $850^{\circ} \mathrm{C}$. In Fig. 2, the film-like alpha phase was formed along grain boundaries in the sample forged at $800{ }^{\circ} \mathrm{C}$ with various deformation ratio. These observations indicate that the morphology of the GB alpha phase is governed forging temperature but not deformation ratio. The deformation ratio governed the volume fraction of GB alpha phase. 
As shown in Fig. 5, the volume fraction of the GB alpha phase decreased with raising forging temperature. The total volume fraction of the alpha phase was almost the same value for the samples forged at temperature range between 700 and $850{ }^{\circ} \mathrm{C}$. The volume fraction of primary alpha phase slightly increased with increase of forging temperature. As a result, the volume fraction of the secondary alpha phase slightly increased with increasing forging temperature because the volume fraction of secondary alpha was estimated by subtracting the volume fraction of primary alpha from total volume fraction of alphaphase. This also indicates the volume fraction of primary alpha phase is governed by solution-treatment temperature, but not forging temperature or deformation ratio.

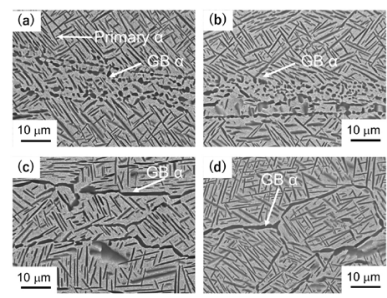

Fig. 4 Backscattered electron images of Ti-17 forged samples at (a) 700, (b) 750 , (c) 800 , and (d) $850{ }^{\circ} \mathrm{C}$ with 75 of deformation ratio followed by air cooling and subjected to solution treatment at $800{ }^{\circ} \mathrm{C}$ for 4 hours followed by water quenching and aging treatment at $620^{\circ} \mathrm{C}$ for 8 hours

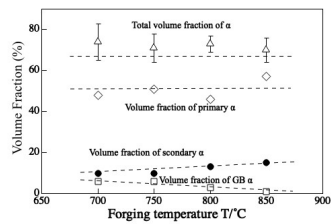

Fig. 5 Volume fraction of the alpha phase for forging temperature [11].

The size of the prior beta phase was also observed for the samples deformed at $800{ }^{\circ} \mathrm{C}$ with various deformation ratio. The inverse pole figure (IPF) maps are indicated in Fig. 6 . The vertical direction is the deformed direction. It is clear that the prior beta phase grains were deformed, collapsed and became flat morphology with increase of deformation ratio. In Fig. 7, the average grain size of the prior beta phase for the horizontal and vertical direction, and the aspect ratio, $d_{H} / d_{V}$ are shown. Here, $d_{H}$ and $d_{V}$ are the diameter for horizontal and vertical directions, respectively. The vertical diameter decreased with increase of deformation ratio. On the other hand, the horizontal diameter increased with increase of deformation ratio up to 67 $\%$, but it decreased above $67 \%$ of the deformation ratio. One possible reason of decrease of the horizontal diameter is refinement of the grains. As a result, the aspect ratio of the prior beta phase increased with increase of deformation ratio and saturated above $67 \%$ of deformation ratio.

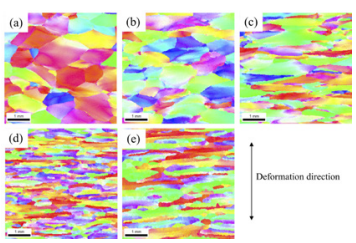

Fig. 6 IPF maps of the prior beta phase in Ti- 17 forged samples at $800{ }^{\circ} \mathrm{C}$ with (a) 33 , (b) 50 , (c) 67 , (d) 75 , and (e) $80 \%$ of deformation ratio followed by air cooling and subjected to solution treatment at $800{ }^{\circ} \mathrm{C}$ for 4 hours followed by water quenching and aging treatment at $620^{\circ} \mathrm{C}$ for 8 hours followed by air cooling.

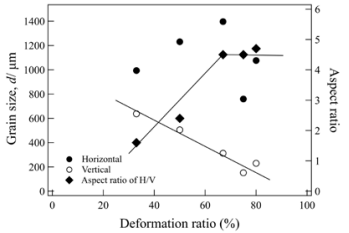




\section{Mechanical properties}

The tensile strength, the $0.2 \%$ proof stress, the elongation and the reduction of area for the deformation ratio are shown in Fig. 8 . The strength was almost the same value and was not depended on the deformation ratio. On the other hand, the elongation and the reduction of area clearly depended on the deformation ratio and increased with increase of the deformation ratio at room temperature and $450{ }^{\circ} \mathrm{C}$. At $600{ }^{\circ} \mathrm{C}$, they were the same value. The aspect ratio of the prior beta phase was drastically changed for the deformation ratio. Then, the elongation and the reduction area is plotted as a function of the aspect ratio of the prior beta grains in Fig. 9. It is clear that the elongation and the reduction of area depended on the aspect ratio of the prior beta grains. Since the tensile test specimens were cut along the horizontal direction, the diameter of collaspped beta grains in the cross section of tensile specimen becames small. It means that grain refinement occurs for the tensile direction, then the elongation and the reduction of area improved.

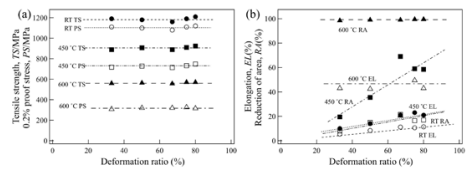

Fig. 8 (a) Tensile strength (TS) and $0.2 \%$ proof stress (PS) and (b) elongation (EL) and reduction of area (RA) at testing temperature of room temperature, 450 , and $600{ }^{\circ} \mathrm{C}$ for deformation ratio.

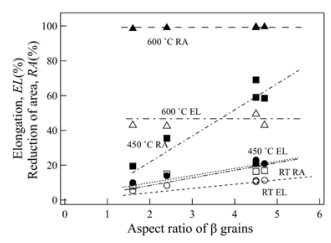

Fig. 9 Elongation (EL) and reduction of area (RA) at testing temperature of room temperature, 450 , and $600{ }^{\circ} \mathrm{C}$ for aspect ratio of beta grains.

The tensile strength, the $0.2 \%$ proof stress, the elongation and the reduction of area of the samples forged at bvarious forging temperature are shown in Fig. 10 [11]. Forging temperature did not affect strength either as well as deformation ratio. It is known that beta alloys are strengthen by the alpha phase [13]. As shown in Fig. 3 and 5, the volume fraction of primary and secondary alpha was not goverend by forging temperature and deformation ratio. This is the reason why the strength of Ti-17 forged at vaeious forging temperature and deformation ratio is the same. The volume fraction or morphlogy of GB alpha phase was governed by deformation ratio or forging temperature, respectively, but since the volume fraction of GB alpha phase is small compraed with the primary and secondary alpha phase, the effect on strength is considered to be small.

On the other hand, the elongation increased with increase forging temperature up to at testing temperature of $450{ }^{\circ} \mathrm{C}$. It is considered that the morphology of GB alpha is considered to affect ductility. That is, the film-like thin alpha phase formed along grain boundaries improved the elongation. It can be said that the aspect ratio of the prior beta grain controlled by deformation ratio and the film-like GB alpha phase formed by solution treatment above $750{ }^{\circ} \mathrm{C}$ improves the elongation of Ti- 17 .

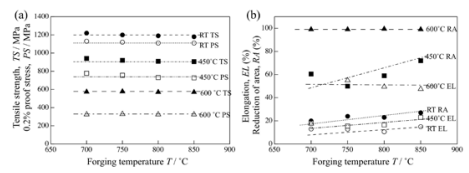

Fig. 10 (a) Tensile strength (TS) and $0.2 \%$ proof stress (PS) and (b) elongation (EL) and reduction of area (RA) at testing temperature of room temperature, 450 , and $600{ }^{\circ} \mathrm{C}$ for forging temperature.

\section{Conclusions}

The microstructure of near beta-Ti alloy, Ti- 17 forged at temperature range from 700 to $850{ }^{\circ} \mathrm{C}$ with the deformation ratio from 33 to $80 \%$ and solution treated at $800{ }^{\circ} \mathrm{C}$ for 4 hours and aged at $620{ }^{\circ} \mathrm{C}$ was investigated. The deformation ratio and forging temperature did not affect the volume fraction and size of the primary and secondary alpha phase. The volume 
fraction and size of the primary alpha phase was controlled by the solution treatment temperature. The forging temperature affected the morphology of GB alpha phase. The granular shape alpha phase was observed for the samples forged at 700 and $750{ }^{\circ} \mathrm{C}$. On the other hand, the film-like thin alpha phase was formed in the samples forged at 800 and $850{ }^{\circ} \mathrm{C}$. It was also found that the volume fraction of GB alpha phase slightly increased at deformation ratio of $80 \%$. The deformation ratio affected the grain size and the aspect ratio of the horizontal and vertical grain size of the prior beta phase. The aspect ratio, $\mathrm{d}_{\mathrm{H}} / \mathrm{d}_{\mathrm{V}}$ increased with increase of deformation ratio. The tensile strength was investigated at room temperature, 450 , and $600{ }^{\circ} \mathrm{C}$. The forging temperature and deformation ratio did not affect the tensile strength. Since the alpha phase strengthen the beta phase, the volume fraction of the alpha phase affects the strength. However, the volume fraction of the primary alpha phase was the same value because the solution-treatment temperature was the same in this study. On the other hand, the forging condition affects the elongation and the reduction of area. The elongation and the reduction of area increased with increase of the aspect ratio of the prior beta grains; that is, increase of the deformation ratio due to refinement of grains in the cross section area of the tensile test specimen. The raising of forging temperature also increased the elongation and the reduction of area because of changing morphology of GB alpha phase from granular to film-like shape.

\section{$\underline{\text { 5. Acknowledgement }}$}

This work was supported by Structural Materials for Innovation, Cross-ministerial Strategic Innovation Promotion Program, Cabinet Office, Government of Japan.Authors appreciate to Dr. E. Chandiran in Tohoku University and Dr. T. Hiroto and Dr. Y. Matsushita in NIMS for measurement of volume fraction of the alpha phase using X-ray diffractometry.

\section{References}

[1] J. R. Wood, P. A. Russo, M. F. Welter, E. M. Crist, Mat. Sci. Eng. A 243 (1998) 109-118.

[2] J. D. C. Teixeria, B. Appolaire, E. Aeby-Gautier, S. Denis, G. Vailletaud, N. Späth, Mat. Sci. And Eng. A 448 (2007) 135-145.

[3] F. Warchomicka, C. Poletti, M. Stockinger, Mat. Sci. Eng. A 528 (2011) 8277-8285.

[4] I. Balasundar, T. Raghu, B. P. Kashyap, Progress in Natural Sci.: Mater. Inter. 236 (2013) 598-607.

[5] G. Lianggang, F. Xiaoguang, Y, Gaofeng, Y, He, Chinese J. of Aeronautics 29, 1 (2016) 30-40

[6] Z. X. Zhang, S. J. Qu, A. H, Feng, J. Shen, D. L. Chen, J. of Alloys and Comp. 718 (2017) 170-181.

[7] K. Yamanaka, H. Matsumoto, A. Chiba, Adv. Eng. Mater., 21, 2 (2019) 1800775.

[8] H. Matsumoto, D. Naito, K. Miyoshi, K. Yamanaka, A, Chiba, Y. Yamabe-Mitarai, STAM, 18, 1 (2017) 893-904.

[9] Y. Nagata, G.Miyamoto, T. Furuhara, Proc. of the PRICM 9 (2016) 654-657.

[10] Y. Kanda, Y. Yoshida, Proc. of Inter. Conf. on Tribology in Manufacturing Process, (2016) 200-207.

[11] Y. Yamabe-Mitarai, S. Kuroda, N. Motohashi, H. Matsumoto, G. Miyamoto, E. Chandiran, Y. Yoshida, Y. Itsumi, Mater. Trans. (2019) in press.

[12] M. Niinomi, T. Akahori, M. Nakai, Y. Koizumi, A. Chiba, T. Nakano, T. Kakeshita, Y. Yamabe-Mitarai, S. Kuroda, N. Motohashi, Y. Itsumi, T. Choda, Mater. Trans. (2019) in press.

[13] G. Lütjering, J.C. Williams, Titanium, 2nd ed., Springer, Berlin, Heidelberg, New York, 2003. 